\title{
THEORETICAL ANALYSIS OF A WET COOLING TOWER FOR FRESH WATER FROM PLUME AND ANALYZING AN INDUSTRIAL COOLING TOWER BASED ON RESULTS
}

\author{
P. Sellamuthu ${ }^{1}$ Dr. C Manoharan ${ }^{2}$ Dr R Senthilkumar ${ }^{3}$ \\ ${ }^{1}$ Associate Professor, Department of Mechanical Engineering, V.M.K.V. Engineering College, \\ Salam 636308 \& Research Scholar, Anna University, Tamil Nadu \\ selsrikanth29@gmail.com \\ 2.Principal, Sapthagiri College of Engineering, Dharmapuri-636205, Tamil Nadu \\ c_m_66@yahoo.co.in \\ ${ }^{3}$ Consultant,Heating Ventilating Air-conditioning (HVAC)systems \\ senthilkumariit@yahoo.com
}

\begin{abstract}
A cooling tower is a heat rejection device which rejects waste heat to the atmosphere through the cooling of a water stream to a lower temperature. The stream of saturated exhaust air leaving the cooling tower called the plume is visible when water vapor it contains condenses in contact with cooler ambient air, like the saturated air in one's breath fogs on a cold day. Under certain conditions, the cooling tower plume may present fogging or icing hazards to its surroundings and gives some environmental problems. To find the solution for this problem a cooling tower has been analysed based on air flow rate through the tower and the cooling load to obtain fresh water yield by utilising plume from cooling tower top. The theoretical analysis gives the values of important parameters Theoretical analysis has been done on wet cooling tower by varying the water flow rate through which affect the performance of a cooling tower such as the cooling range, effectiveness, approach, fresh water yield etc. Then with the conditions of a trials from the analysis, the mass flow rate of water in the cooling tower was scaled up to match the mass flow rate of water in an industrial cooling tower. This helps in obtaining the mass flow rate of the air and fresh water yield through the industrial cooling tower
\end{abstract}

KEYWORDS: cooling range, effectiveness, mass of evaporated water,plume, fresh water.

ACADEMIC DISCIPLINE AND SUB-DISCIPLINES

Mechanical Engineering, Heat Transfer

\section{TYPE (METHOD/APPROACH)}

Theoretical Analysis

\section{INTRODUCTION}

The lack of water resources all around the world gives a view to us to conserve the water in a better manner. In thermal power plants, plume/ water vapour (Hot air with water vapour normally called as plume) released by evaporation in cooling towers which is left to atmosphere as a waste. This wasted water vapour is being collected and condensed to get fresh water by a condenser. This fresh water is used for several applications of that power plant itself. A few researches have been carried out for analysis of cooling tower to utilize the waste plume. Cooling towers make use of evaporation whereby some of the water is evaporated into a moving air stream and subsequently discharged into the atmosphere.The evaporated water vapour is condensed to obtain fresh water with help of a designed condenser. The air flow in cooling towers may be parallel flow, cross flow or counter flow, may make direct contact or indirect contact with the hot water, and may be natural or forced flow. In forced flow either a fan or a centrifugal blower is used to force the air through the cooling tower. Usually, a centrifugal blower is used to force the

air from the bottom of the cooling tower to the top. The water flows from the top of the cooling tower, through the packing material or fills. The packing material or fills are provided to slow down the water, to spread the water and expose it as an extended surface to the air flowing in at atmospheric temperature, to ensure even distribution of water throughout the cooling tower. Heat transfer takes place through conduction, convection, radiation and evaporation out of which the heat transfer through evaporation is the most important phenomenon as it contributes the maximum. Evaporation is utilized to its fullest extent in cooling towers, which are designed to expose the maximum transient water surface to the maximum flow of air for the longest period of time. The water which is cooled is collected at the bottom of the cooling tower and is used in condensers to condense the used steam in steam power plants into water which would be sent back into the boilers to be converted back into steam to generate power. The water which is used to condense the steam gets heated up again and is sent to the cooling tower again. This process repeats itself as a cycle. The hot air from the cooling tower exits from its top into the atmosphere. Four different cooling loads $0.1 \mathrm{~kW}$, $0.6 \mathrm{~kW}, 1.1 \mathrm{~kW}$ and $1.6 \mathrm{~kW}$, such a way that four different water input temperatures have been varied, three different water flow rates $0.035 \mathrm{~kg} / \mathrm{s}, 0.04 \mathrm{~kg} / \mathrm{s}$ and $0.045 \mathrm{~kg} / \mathrm{s}$ and four different air flow rates were taken for the analysis. The governing equations of the cooling tower have been obtained and solved those equations to get important parameters viz, range, effectiveness, fresh water yield etc. 


\section{LITERATURE SURVEY}

V.D papaefthimiou et .al [1] investigated that minimizing the inlet wet bulb temperature the affinity of air for water vapour absorption is increased.The work done by Ronak shah et. al [2] Shown that the performance of cooling tower increase with increase in rate of air flow and with increase in water to air mass ratio the characteristic of cooling tower decreases. Work done Bilal qureshi et at al[3] shown that an experimental data as well as numerical values calculated solved by Engineering Equation solver (EES) program to make a prediction for evaporation losses in a medium sized tower. H.maromveh et . al[4] dealt the solar desalination system with humidification and dehumidification. The relation expressing the variation of cooling tower characteristics with liquid to gas mass flow rate.Work done byS.K.Tyagi et. al[5] detailed the economic study for the solar collector heat pump and biogas systems to control the visible plume from wet cooling towers of commercial building. The study carried out by considering the possible constraints and comparison using total cost ,consists of investment cost and operational cost. Work done by N.E.Koeman-stein et al[6] show that membrance distillation could use thermal energy. This reduces the need of cooling capacity and reduced energy and chemicals demands and green house gas emission .Milosavljevic et .al[7] shown that CFD simulation to predict the external air flow around the cooling tower and backflow in different weather conditions in summer and winter pooriya shahali et . al [8] detailed that the water temperature difference and cooling efficiency decreases through enhancing the water flow rate reached at lower and higher mass flow rates of air inlet water temperature. M.M.A. sarkar et . al [9]detailed that the pressure drop for the fin tubes was nearly two times higher than that of bare tubes in both modes for considerable enhancement of cooling capacity Work done by C.A.X Marques et .al[10] detailed in each case the water loss through evaporation and the energy consumption in the cooling tower were estimated in order to analyse its co-efficiency. Work done by R.Terbanche et .al[11] detailed on drop size distribution the air and water flow rates are varied to investigation their influence on drop Geoming Ge, Fu xiao et.al [12] investigated that discharge recirculation results in increased frequency of visible plume occurrence. These results can make the predictions of the plume potential and the design of the plume abatement system and provided guidelines for this research. This paper presents the evaluation of the plume potential of the evaporative cooling towers using alternative control Previous studies on evaporative cooling towers based on the characteristics and design of cooling towers have provided guidelines for this research.

\section{HEAT TRANSFER PROCESS}

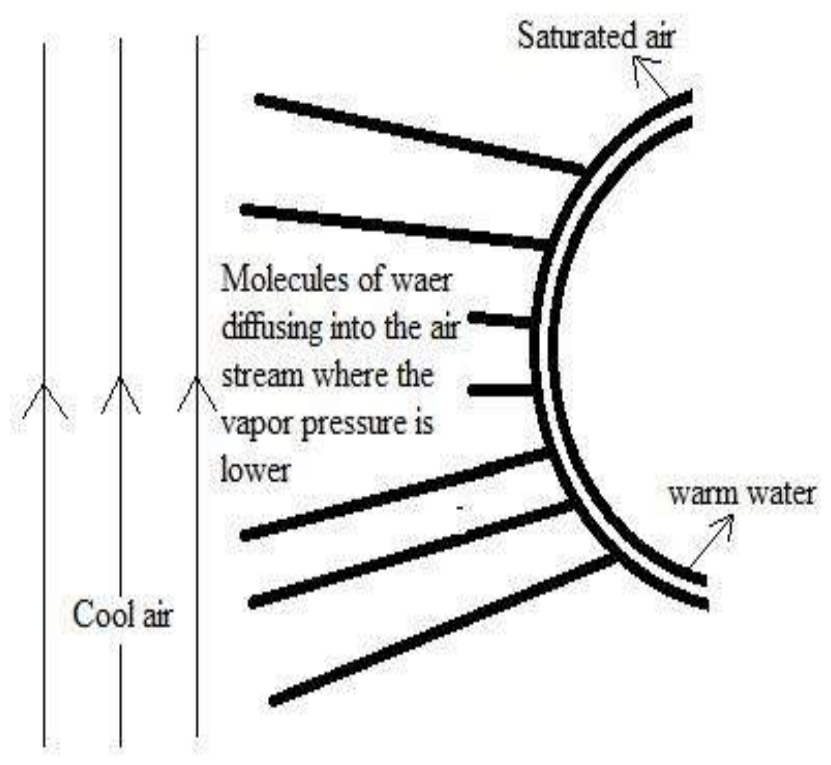

Fig.1-Heat transfer process

Fig1 shown in considered as the surface of a warm droplet of water to be in contact with air stream. In a cooling tower cooling process takes place mostly by evaporation process takes places mostly by evaporation process. The molecules of water diffuse from the surface into the surrounding air so cooling takes places. The air steam have contact with water molecules is assumed to be completely saturated the moisture (The evaporated water) in the saturated air diffuse into the stream ahead of it whose vapour pressure is [8] imperatively lower. The molecules of water get replaced by the layer of molecules present at the surface of the water. The energy replaced to this is taken from the rest of the liquid and water gets cooled continuously for effective cooling to take place it is neede to circulate unsaturated air through the cooling towers. 


\section{SCHEMATIC FOR ANALYSIS}

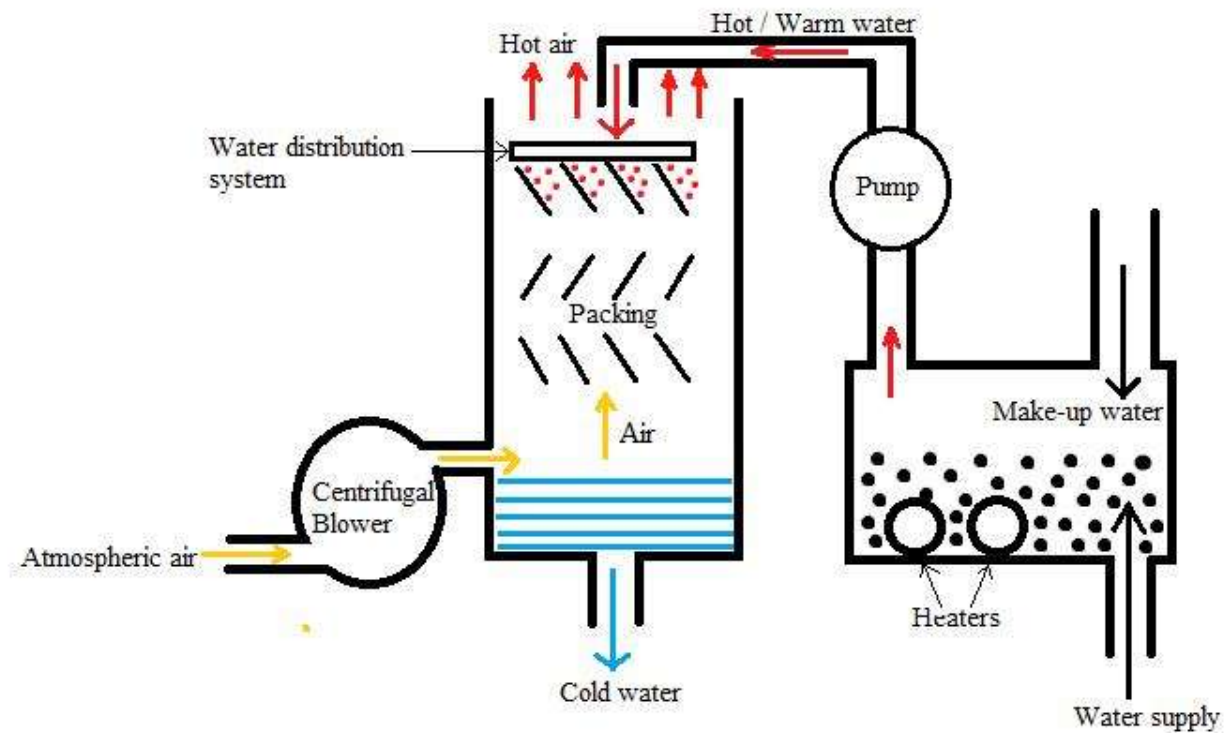

Fig.2- Schematic of the experimental setup of a laboratory scale cooling tower

\subsection{DESCRIPTION}

The experimental setup of a laboratory scale cooling tower consists of a water distribution system, packing centrifugal blower, pump, glass column, load tank, makeup tank, float valve, variable area flow meter, inclined tube manometer, connections for orifice differential pressure,connection for pressure drop across packing, droplet arrester, thermometer for measuring the inlet and outlet temperature of air and water. To slow down the water flow from the tower the packed glass column is used. The objective of the analysis was to calculate the amount of water evaporated from cooling tower at different conditions. cooling range, approach, efficiency, effectiveness, and the study of characteristics of cooling tower by plotting graphs between various quantities .

\section{DEFINITIONS}

Cooling range is the difference between the cooling tower inlet and our temperature. The range is high means the efficiency of cooling tower is high. So the temperature of the water is reduced effectively. The difference between the cooling tower outlet temperature of water and ambient wet bulb temperature is called approach. The approach should be low to the greater performance of cooling tower the ratio of range and the ideal range means the effectiveness. The effectiveness should be higher for higher performance of cooling tower.

\section{THEORETICAL ANALYSIS OF INDUSTRIAL COOLING TOWER}

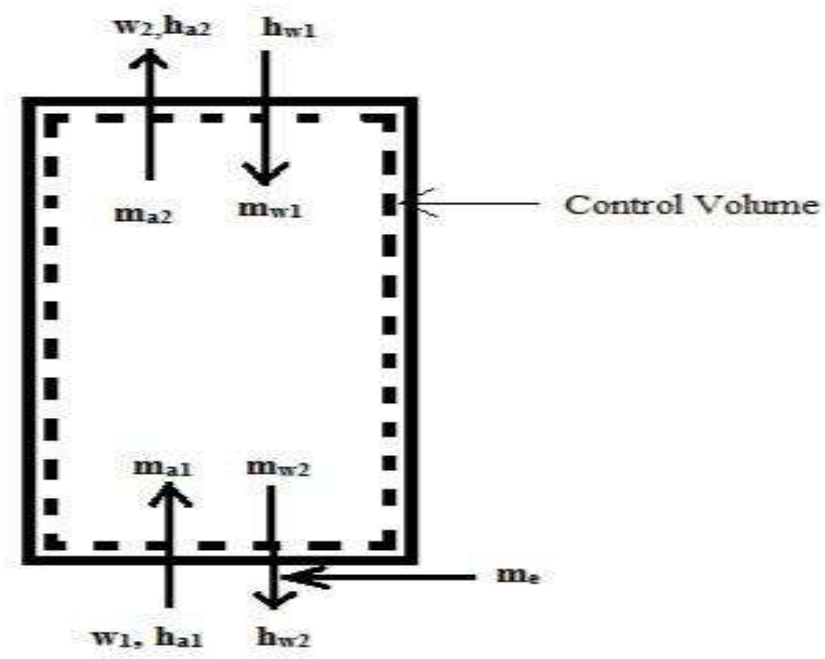

Fig. 3- Control Volume Diagram 
Dry air mass balance:

$$
\mathrm{ma} 1=\mathrm{ma} 2=\mathrm{ma}
$$

Water mass balance:

$$
m_{\mathrm{w} 1}+\mathrm{m}_{\mathrm{a} 1} \times \mathrm{w}_{1}=\mathrm{m}_{\mathrm{w} 2}+\mathrm{m}_{\mathrm{a} 2} \times \mathrm{w}_{2}
$$

$$
\text { or } \quad m_{w 1}-m_{w 2}=m_{a} \times\left(w_{2}-w_{1}\right)=m_{e}
$$

Energy balance:

$$
\left(m_{\mathrm{a} 1} \times h_{\mathrm{a} 1}\right)+\left(m_{\mathrm{w} 1} \times h_{\mathrm{w} 1}\right)=\left(m_{\mathrm{a} 2} \times h_{\mathrm{a} 2}\right)+\left(m_{\mathrm{w} 2} \times h_{\mathrm{w} 2}\right)
$$

$$
\text { or } \quad m_{w 1} \times h_{w 1}=m_{a} \times\left(h_{a 2}-h_{a 1}\right)+\left(m_{w 1}-m_{e}\right) \times h_{w 2}
$$

Solving for $m_{a}$ from the above equations we get,

$$
\begin{aligned}
m_{a}=\quad & m w 1 \times(h w 1-h w 2) \\
v_{1}= & m_{a} \times v_{1} \\
m_{e}= & \left.m_{a} \times\left(h_{2}-h_{a 1}\right)-\left(w_{2}-w_{1}\right) \times h_{w 2}\right]
\end{aligned}
$$

An industrial cooling tower that has a cooling load of $330 \mathrm{MW}$ can have a water flow rate upto $24,000 \mathrm{~m}^{3} / \mathrm{hr}$ which turns out to be $6666.667 \mathrm{~kg} / \mathrm{sec}$ and assuming dry bulb temperature at inlet and outlet of air, relative humidity of air at inlet and outlet, temperature of water at inlet and outlet to be $20^{\circ} \mathrm{C}, 35^{\circ} \mathrm{C}, 70 \%, 100 \%, 40^{\circ} \mathrm{C}$ and $30^{\circ} \mathrm{C}$ the values of $\mathrm{m}_{\mathrm{a}}$ and $m_{\mathrm{e}}$ were obtained and the results are shown in Fig.8 Fig.9

\section{RESULTS AND DISCUSSION}

\section{1) Graph between Cooling Range and Effectiveness}

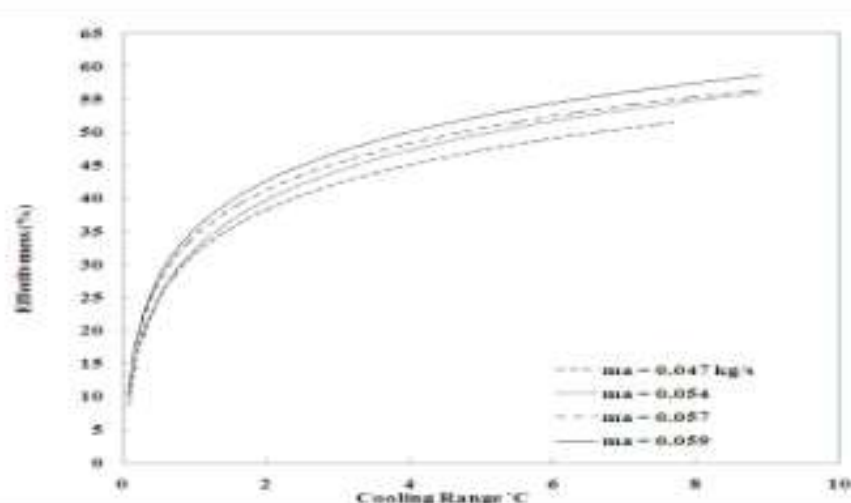

Fig. 4- Effect of Cooling Range on Effectiveness

2) Graph between Water flow rate and mass of evaporated water

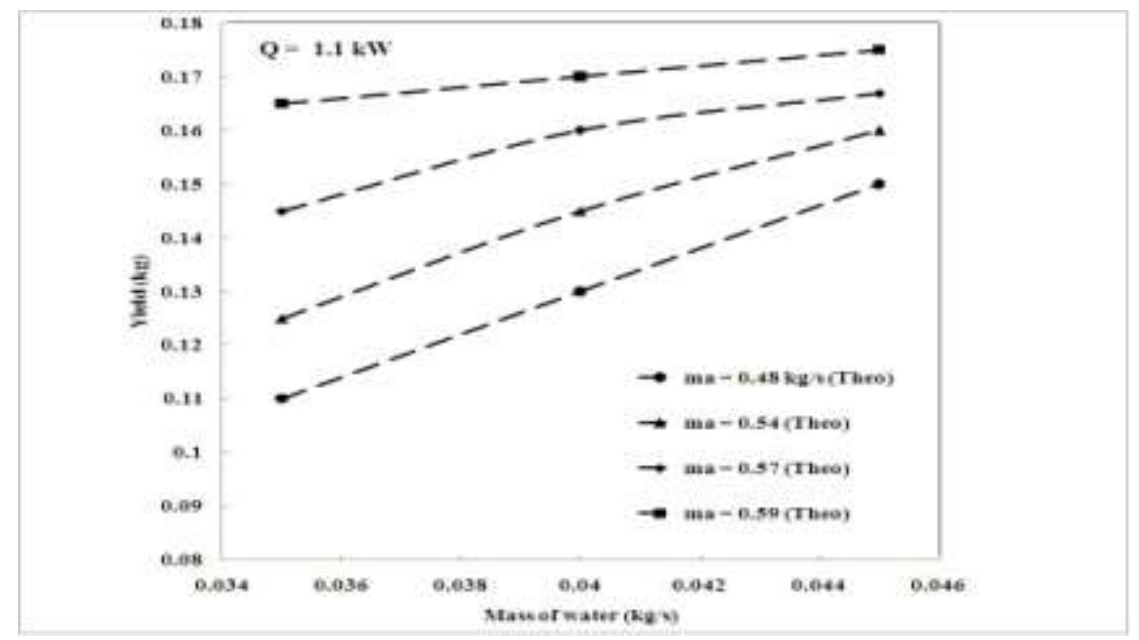

Fig. 5- Effect of $m_{w}$ on Me 
3) Graph between air flow rate and mass of evaporated water

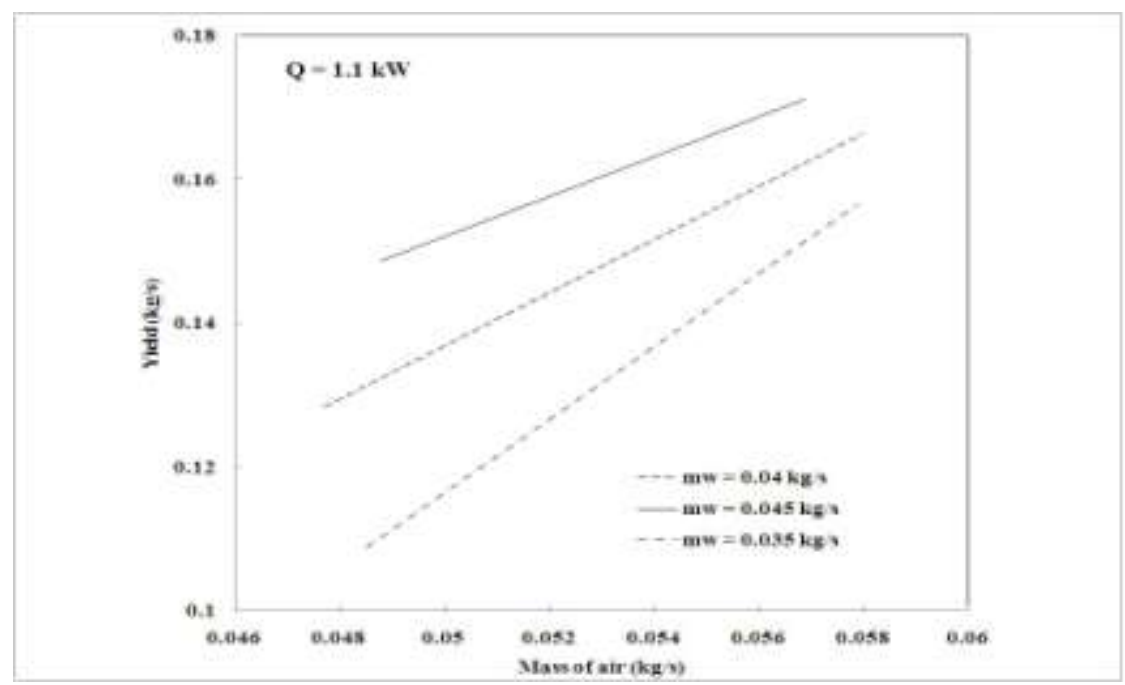

Fig. 6 Effect of $m_{a}$ on Me

4) Graph between cooling load and water temperature $\left(c^{0}\right)$

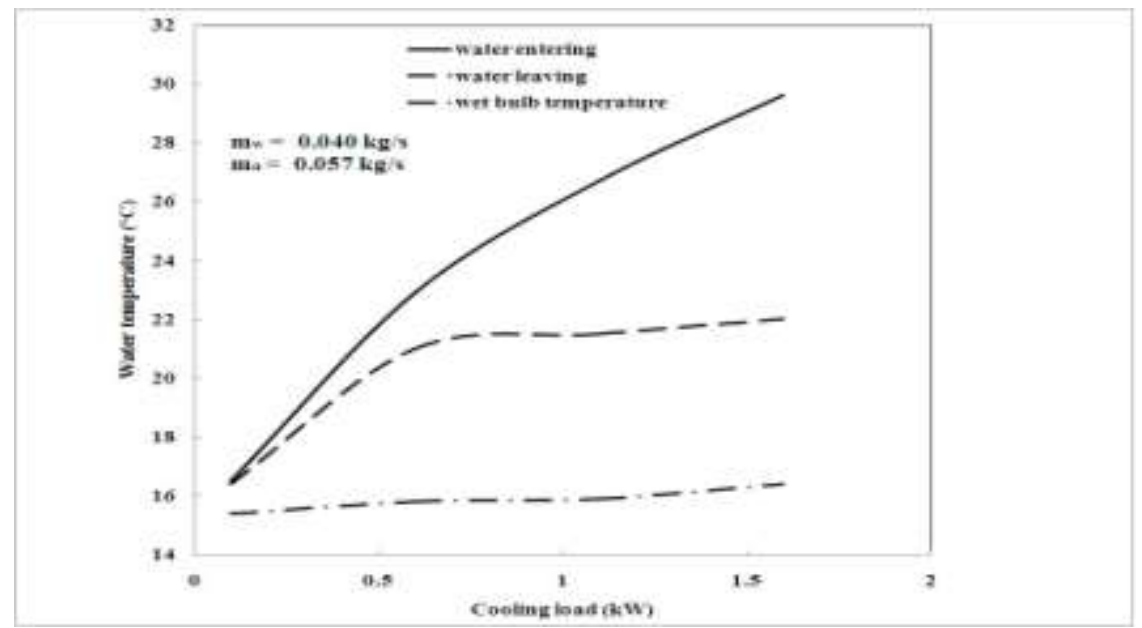

Fig. 7- Variation of cooling load on water temperature

5) Graph between Water flow rate and mass of evaporated water \& Air flow rate and mass of evaporated water

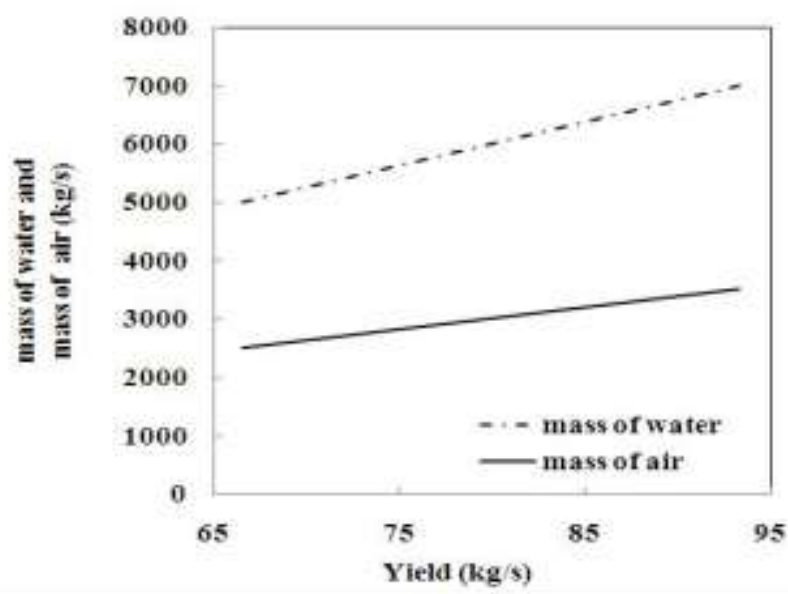

Fig. 8- Effect of yield on $m_{w}$ and $m_{a}$ 
6) Graph between Water flow rate and mass of evaporated water \& Air flow rate and mass of evaporated water for 840 MW Power Plant Cooling Tower

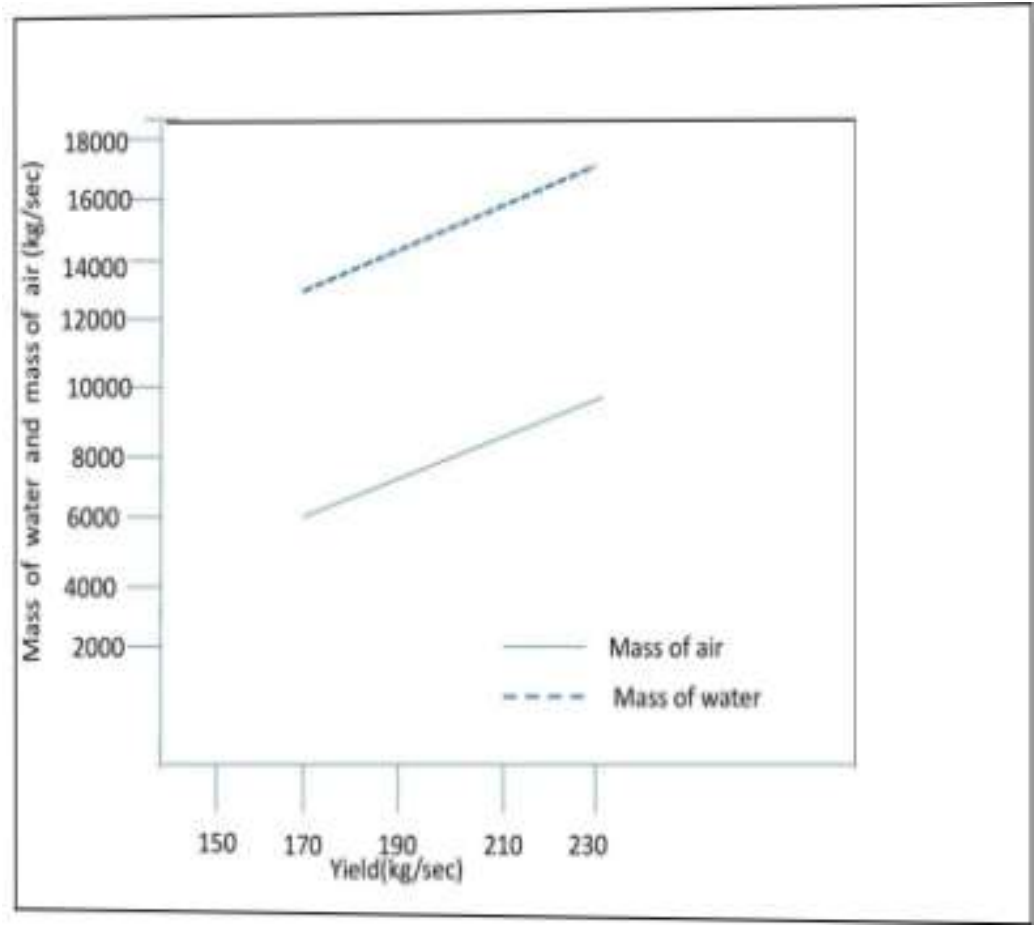

Fig. 9- Effect of yield on $\mathrm{m}_{\mathrm{w}}$ and $\mathrm{m}_{\mathrm{a}}$ for $840 \mathrm{MW}$ Power Plant Cooling Tower

Fig. 4 shows the effect of cooling range on effectiveness (\%) at different air flow rates where $m_{w}$ was kept constant. When cooling range increases the effectiveness increases because range is a function of temperature and the effectiveness becomes constant at high temperatures due to the evaporation loss and enthalpy difference between the air and hot water. And as the air flow rate increases the effectiveness also increases. For the range to increase for a fixed value of water inlet temperature the water outlet temperature must decrease. It means that the performance of

the cooling tower is high when outlet temperature is decreased. Higher performance would account to the increased effectiveness of the cooling tower. When the air flow rate increases the water particles have more air to exchange the heat they posses and hence the water would cool down more effectively. This contributes to the increase in effectiveness as the air flow rate increases.

Fig. 5 gives the effect of water flow rate on mass of evaporated water at different air flow rates. When the water flow rate increases the mass of evaporated water increases. And as the air flow rate increases the mass of evaporated water also increases. From the theoretical analysis the equations show that the water flow rate is proportional to the air flow rate and air flow rate is proportional to the mass of evaporated water. Also, practically increasing water flow rate implies that there is more water available and hence more evaporation. But, however the rate of evaporation doesn't increase in a very rapid manner with respect to increase in water flow rate.

Fig. 6 gives the effect of air flow rate on mass of evaporated water at different water flow rates. As the air flow rate increases the mass of evaporated water also increases. And for increasing water flow rates the mass of evaporated water increases. Increase in the air flow rate helps in more diffusion of the water particles into the unsaturated air and hence more evaporation takes place. This increases the mass of evaporated water.

Fig. 7 shows the temperatures of water entering the tower, water leaving the tower and wet bulb temperature at different cooling loads. The cooling range increases as the cooling load increases. The difference between the temperature of water entering and the wet bulb temperature is known as ideal range. The ideal range also increases with increase in load. With increase in cooling load the temperature of the inlet water increases. For a fixed value of the outlet temperature the range would increase if the water inlet temperature increases. Hence the difference between them increases which is nothing but the range.

Fig. 8 gives the effect of water flow rate on mass of evaporated water, air flow rate on mass of evaporated water with the values obtained from [6], Considering the temperature conditions to be constant water flow rate, air flow rate and mass of evaporated water are all directly proportional to each other.

Fig. 9 gives the effect of water flow rate on mass of evaporated water, air flow rate on mass of evaporated water with the values obtained from [6] for 840 MW Power Plant Cooling Tower. Considering the temperature conditions to be constant water flow rate, air flow rate and mass of evaporated water are all directly proportional to each other. 


\section{CONCLUSION}

It has been found from the theoretical analysis on wet cooling tower, when the cooling range increases, the effectiveness increases and becomes constant at higher temperatures. With increase of cooling load the temperature of inlet water temperature increases for increasing water flow rate, air flow rate, Which means the evaporated water increases. The water flow rate, air flow rate and rated of evaporation are proportional to each other at certain temperature conditions. Using cooling tower in industries would help in reusing $98 \%$ of water that is used for cooling purposes.

\section{NOMENCLATURE}

$\mathrm{m}_{\mathrm{a} 1}=$ mass of air at inlet $(\mathrm{kg} / \mathrm{s})$

$\mathrm{m}_{\mathrm{a} 2}=$ mass of air at outlet $(\mathrm{kg} / \mathrm{s})$

$\mathrm{m}_{\mathrm{w} 1}=$ mass of water at inlet $(\mathrm{kg} / \mathrm{s})$

$\mathrm{m}_{\mathrm{w} 2}=$ mass of water at outlet $(\mathrm{kg} / \mathrm{s})$

$\mathrm{h}_{\mathrm{a} 1}=$ specific enthalpy of air at inlet $(\mathrm{kJ} / \mathrm{kg})$

$\mathrm{h}_{\mathrm{a} 2}=$ specific enthalpy of air at outlet $(\mathrm{kJ} / \mathrm{kg})$

$h_{w 1}=$ enthalpy of water at the inlet $(\mathrm{kJ} / \mathrm{kg})$

$\mathrm{h}_{\mathrm{w} 2}=$ enthalpy of water at the outlet $(\mathrm{kJ} / \mathrm{kg})$

$\mathrm{w}_{1}=$ specific humidity of water at the inlet $(\mathrm{kg} / \mathrm{kg}$ of dry air)

$\mathrm{W}_{2}=$ specific humidity of water at the outlet $(\mathrm{kg} / \mathrm{kg}$ of dry air)

$v_{1}=$ specific volume of air at the inlet $\left(\mathrm{m}^{3} / \mathrm{kg}\right)$

$\mathrm{V}_{1}=$ volume flow rate of the air at the inlet $\left(\mathrm{m}^{3} / \mathrm{s}\right)$

$\mathrm{m}_{\mathrm{e}}=$ mass flow rate of make-up water $(\mathrm{kg} / \mathrm{sec})$

$\mathrm{M}_{\mathrm{e}}=$ mass of water that evaporated from the cooling tower $(\mathrm{kg})$

\section{REFERENCES:}

1. V.D.Papaefthimiou T.C.Zannis J. 2006. Thermodynamic study of wet cooling tower performance.

2. Ronak shah, Trupati Rathod J.2012.Thermal design of cooling tower.

3. Bilal Ahmed Qureshi and Syed M.Zubair J.2006. Prediction of Evaporation losses in wet cooling tower.

4. H.Marmouch J.orfi J.2008. Experimental and theoretical study on the effect of cooling tower on solar desalination system.

5. S.K.Tyagi, S.R.Park J.2009. Economical and thermal optimization of possible options to control visible plume from wet cooling towers.

6. N.E.Koeman-stein, R.J.M.Creusen J.2016.Membrance distillation of industrial cooling tower blow down water.

7. N.Milosavljevic and heikkila J.2001.A.Comprehensive Approach to cooling tower design.

8. Pooriya shahali, mehdi Rahmati J.2016 Experimental study on improving operating conditions of wet cooling tower using various rib numbers of packing.

9. M.M.ASARKAR. G.J Shim J.2009.Enhancement of cooling capacity in a hybride closed circuit cooling tower.

10. C.A.X.Marques, C.H.Fontes J.2009.Efficiency control in acommertial counter flow wet cooling tower.

11. R.Terblance.HCR,Reuter J.2009.drop size distribution below different wet cooling tower fills.

12. Gaoming Ge, fu xiao, shengwei wang J.2012.Effects of discharge recirculation in cooling towers on energy efficiency nad visible plume potential of chilling plants.

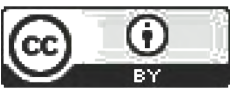

This work is licensed under a Creative Commons Attribution 4.0 International License. 